\title{
BMJ Global Health Why global health can offer more on gender
}

\author{
Claire Somerville
}

To cite: Somerville C. Why global health can offer more on gender. BMJ Global Health 2020;5:e002328. doi:10.1136/ bmjgh-2020-002328

Handling editor Seye Abimbola

Received 20 January 2020 Revised 17 March 2020 Accepted 21 March 2020
Check for updates

\section{(c) Author(s) (or their} employer(s)) 2020. Re-use permitted under CC BY-NC. No commercial re-use. See rights and permissions. Published by BMJ

Gender Centre, Graduate Institute of International and Development Studies, Geneva, Switzerland

\section{Correspondence to} Dr Claire Somerville; claire.somerville@ graduateinstitute.ch
Progress towards gender equality is often measured against time and in years-be those reflections back marking progress to date or predictions forward to inspire and galvanise action in the present. As we enter 2020, and activity around the United Nations Beijing+25 gathers steam, multiple new sources of data will likely produce innovation on indexes, predictive models, indicators and markers, which will help 'measure' gender relations and the role gender and other inequities play in areas of global policy and politics, including global health. Measurements are important, and there are many out there; but, so too are fundamental understandings and theoretical abstractions; and in this we have some work ahead.

In the field of gender, most especially in studies of gender in global health, we would do well to recall the psychologist Kurt Lewin's maxim: "there is nothing as practical as a good theory"-for it is in this area, ${ }^{1}$ and in the shadow of 25 years of gender mainstreaming, that an intersectional gendered understanding of global health can most contribute and benefit right now.

The need to advance our conceptual theorising is not to deny the considerable work that global health actors have undertaken in contributing to the global gender agenda, specifically at WHO since Director General Hiroshi Nakajima's Beijing statement outlining sex-specific commitments to the health of women and reproductive health, and violence against women. These commitments were further actioned with a number of World Health Assembly resolutions between 1997 and 2012 that covered a range of issues from recruitment to gender as a social determinant of health.

The push, however, during these earlier years of post-Beijing focused around the burgeoning area of technologies of gender mainstreaming, a concept where feminist knowledge becomes part of the governance of conduct, or technology of government. ${ }^{2}$
Summary box

The interdisciplinary field of global health is an untapped reservoir of thinking around gender.

- Gender scholars in global health should critically revisit social constructivism in the practice of global health research, policy and programming.

- The practicality of good theory beyond social constructivism is a critical next step in global health

- Critical rethinking of the epistemologies of biologies and sexes from an interdisciplinary global health perspective can usefully challenge our thinking in gender studies.

- Intersectionality, power and bipower, knowledge and governance are some of the areas where global health can contribute further.

These were seeded with campaigns to raise awareness around gender inequalities that were embedded deep in the organisational structures that deliver global health. Mainstreaming initially manifested itself in the inclusion of gender terminologies in the vast reams of written texts that accompany the processes and programming of health from global to national and, it was hoped, local levels of administration. Awareness-raising took shape through the medium of language with the expectation that this would at least trigger actions to address gender and other inequalities in the planning and delivery of health policy and services.

With time, the need to better communicate what was understood as gender-and hence the need for definitions-arose, and discourses around social constructions of the concept provided the necessary epistemological space that could accommodate change. Defined as socially constructed, gender could be re-constructed outside of the patriarchal relations of power that resulted in systemic subordination of women. The patriarchal gender order could be transformed if only mainstreaming and other technologies of change could be leveraged in full to upend the relations of power and shift organisational 
'cultures' in a linear move from gender blindness, through awareness, to transformation.

In parallel, a shift from a focus on equality to equity is observed, ${ }^{34}$ and this is especially present in the policies and communications that accompany a concern with justice and distribution of power and resources. Critiques of gender mainstreaming ${ }^{5-7}$ also emphasised a concern that the institutionalisation of feminist knowledge as gender expertise risk depoliticising practice. ${ }^{89}$

In global health, this framing has generated a plethora of normative and action-oriented moves often led by the key global health actors such as WHO, and quite notably the newer Public-Private Partnerships (PPPs) such as Gavi, the Vaccine Alliance and Product Development Partnership (PDPs) such as FIND, took on mainstreaming from their inception with commitments to equity built into their early missions and strategic planning.

But in among these activities over the two decades, little critical reflection or innovative theorising on the broader social role of gender in health has been forthcoming. The paradigm of social constructionism has served as the theoretical underpinning of definition. As such, social constructivism has served a mainly political purpose. It is, by definition, axiomatically changeable. And change is the goal of mainstreaming and other movements that strive to eliminate discrimination and advance gender equality. The definition necessarily needed to be one that could be operationalised, implemented and evaluated as part of change towards greater-and measurable-equality. So socially constructed that, in moments that might be historically viewed as problematic, gender became the metaphorical bucket in which all that was not biological could be easily housed.

That biological sex, and, it here for the first time I refer to sex, has also been theorised as socially constructed by Judith Butler since the early $1990 \mathrm{~s}^{10}$ and remains an area still in need of significant thinking in view of the emergence of considerable new evidence on spectrums and cellular-level science. ${ }^{10}{ }^{11}$ Definitions of sex in elite sport and the use of hormone measures as markers of sex in single-sex competitive sport are just one space in which the social construction of binary sex are being played out internationally. ${ }^{12}$ And given the politics of biopower involved in these sex constructions, which often call on medical expertise as arbiters of classification boundaries, ${ }^{13}$ it is critical that the wider global health community engage theoretically.

The medical professions, natural scientists and health researchers have been comfortable with sex-at least in its binary form and also as a classificatory group of intersex conditions with medically tangible characteristics-and have also come to embrace the post-Beijing requirements to advance gender equality and implement technologies of gender mainstreaming. But we have been less proactive with engaging in the theoretical and conceptual space of understanding gender as a human force and also, importantly, advancing the science around the constitution of sex and the epistemological foundations of what we mean as 'biological'. As a global health community, we have among us biologists and natural scientists whose contribution to the entanglements of boundaries and classifications of sex and gender should be welcomed as the foundations of all our areas of study and knowledge are disrupted and subjected to change that is often paradigm shifting. While global health continues to view gender as socially constructed, as against biological sex, as categorical, it fails to leverage the reservoirs of new cellular, genomic and epigenetic knowledge that disrupt the core against which gender theorising and polices of mainstreaming have developed. From the field of gender studies, increased understanding and usage of intersectional approaches to understanding global health are necessary as intersectionality scholars have long since argued, ${ }^{14}{ }^{15}$ gender cannot be taken in isolation of other axes of discrimination and disadvantage, privilege and advantage. It is the merging of these otherwise, siloed paradigms of thinking that remain wedded to enlightenment thinking that prevent us from advancing the ways in which we analyse the gendered dimensions of health.

Global health, therefore, has significant contribution to make to our understanding of gender far beyond health and medicine. Most importantly, I argue that the furthering of theoretical and conceptual thinking from this vast interdisciplinary reservoir will advance health in ways we have yet to uncover. As a concept of power, gender operates everywhere; it is pervasive; it is one of the ways by which we organise societies and therefore also our health and medical systems. And as such, gender is by definition a determinant of health, even if gender equality were achieved. This is why we need to move our understanding beyond only technologies of mainstreaming and measures of gender equality, to generate theory with practical usage, and to ensure that conceptual knowledge of gender in global health transcends fields of study, policy and practice.

Contributors The comment is the sole work of the author.

Funding The authors have not declared a specific grant for this research from any funding agency in the public, commercial or not-for-profit sectors.

Competing interests None declared.

Patient consent for publication Not required.

Provenance and peer review Not commissioned; externally peer reviewed.

Data availability statement Data sharing is not applicable to this article as no new data were created or analyzed in this study.

Open access This is an open access article distributed in accordance with the Creative Commons Attribution Non Commercial (CC BY-NC 4.0) license, which permits others to distribute, remix, adapt, build upon this work non-commercially, and license their derivative works on different terms, provided the original work is properly cited, appropriate credit is given, any changes made indicated, and the use is non-commercial. See: http://creativecommons.org/licenses/by-nc/4.0/.

\section{ORCID iD}

Claire Somerville http://orcid.org/0000-0002-2335-160X

\section{REFERENCES}

1 Lewin K. Psychology and the process of group living. J Soc Psychol $1943 ; 17: 113-31$. 
2 Prügl E. Diversity management and gender mainstreaming as technologies of government. Pol \& Gen 2011;7:71-89.

3 Doyal L. Gender equity in health: debates and dilemmas. Soc Sci Med 2000:51:931-9.

4 Jones CM, Gautier L, Kadio K, et al. Equity in the gender equality movement in global health. Lancet 2018;392:e2-3.

5 True J, Parisi L. Gender mainstreaming strategies in international governance. In: Feminist strategies in international governance. Routledge, 2013: 59-78.

6 Walby S. Gender mainstreaming: productive tensions in theory and practice. Soc Polit 2005;12:321-43.

7 Hankivsky O, Gendervs. Gender vs. diversity mainstreaming: a preliminary examination of the role and transformative potential of feminist theory. Can J Pol Sci 2005;38:977-1001.

8 Prügl E. How to wield feminist power. In: The politics of feminist knowledge transfer. Springer, 2016: 25-42.
9 Mukhopadhyay M. Mainstreaming gender or "streaming" gender away: feminists marooned in the development business. In: The Palgrave handbook of gender and development. Springer, 2016: 77-91.

10 Ainsworth C. Sex redefined. Nature 2015;518:288-91.

11 Müller R, Hanson C, Hanson M, et al. The biosocial genome? Interdisciplinary perspectives on environmental epigenetics, health and society. EMBO Rep 2017;18:1677-82.

12 Erikainen S. Gender verification and the making of the female body in sport: a history of the present. Routledge, 2019.

13 Pape M. Expertise and non-binary bodies: sex, gender and the case of Dutee Chand. Body Soc 2019;25:3-28.

14 Hankivsky O. Women's health, men's health, and gender and health: implications of intersectionality. Soc Sci Med 2012;74:1712-20.

15 Hankivsky O, Cormier R. Intersectionality: moving women's health research and policy forward. Vancouver: Women's Health Research Network, 2009 